\title{
Characterization of Pd-mordenite Catalysts for NO Decomposition
}

\author{
Andréa Marins de Oliveira • Ignácio Costilla • \\ Carlos Gigola $\cdot$ Ione Maluf Baibich • \\ Victor Teixeira da Silva $\cdot$ Sibele B. Castellã Pergher
}

Received: 21 May 2009/Accepted: 26 February 2010/Published online: 1 April 2010

(C) Springer Science+Business Media, LLC 2010

\begin{abstract}
The aim of this study was to characterize Pd catalysts supported on three different mordenite zeolites (a commercial sample and two laboratory preparations) previously tested for the $\mathrm{NO}$ decomposition reaction. $\mathrm{H}_{2}$ chemisorption, TPR, FTIR spectroscopy of adsorbed CO and NO, DRS UV-vis and TPD of NO were used to characterize the catalysts. After reduction at $573 \mathrm{~K}$ a large fraction of $\mathrm{Pd}^{\mathrm{o}}$ particles and some $\mathrm{Pd}^{2+}$ ions were found in the commercial sample and one laboratory preparation. In contrast a sample prepared with a mordenite synthesized using a natural clay was found to exhibit mainly ionic Pd. The amount of $\mathrm{Pd}^{\mathrm{O}}(\mathrm{PdO})$ relative to $\mathrm{Pd}^{2+}$ depends on the oxidation temperature and the metal loading. The catalysts exhibited similar levels of activity for the NO decomposition reaction at $673 \mathrm{~K}$ but a different selectivity to $\mathrm{N}_{2} \mathrm{O}$. This behavior was related to differences in metal dispersion and other surface conditions that influence the formation of PdO particles.
\end{abstract}

\footnotetext{
A. M. de Oliveira · I. M. Baibich

Instituto de Química, Universidade Federal do Rio Grande do Sul, CP 15003, Porto Alegre, RS 91501-970, Brazil

I. Costilla $\cdot$ C. Gigola

PLAPIQUI, km 7 Camino "La Carrindanga", C.C. 717-8000

Bahia Blanca, Argentina

V. T. da Silva

Programa de Engenharia Química/NUCAT/COPPE_UFRJ-Ilha do Fundao-Centro de Tecnologia, Sala G-116, Rio de janeiro, RJ, Brazil

\section{S. B. Castellã Pergher $(\square)$}

Departamento de Química, Universidade Regional Integrada do Alto Uruguai e das Missões-campus Erechim, Av. Sete de Setembro, 1621, Erechim, RS 99700-000, Brazil

e-mail: pergher@uricer.edu.br
}

Keywords $\mathrm{Pd} \cdot$ Mordenite $\cdot \mathrm{CO}$ and $\mathrm{NO}$ adsorption . TPR · TPD of NO

\section{Introduction}

The use of transition metals supported on zeolite for the decomposition of $\mathrm{NO}$ is the most suitable solution for nitrogen oxide reduction in pollution emission control because this process does not require the addition of reagents such as hydrocarbons, ammonia, $\mathrm{CO}$ or hydrogen [1-4]. The zeolite system CuZSM-5 has been intensively studied due to its high NO decomposition activity [5].

The activities of zeolite catalysts containing transition metals are related to the type of metal and the properties of the zeolite, including pore dimensions and active site accessibility [6]. Palladium supported on zeolites leads to the formation of catalysts with high $\mathrm{NO}_{x}$ reduction activity. The importance of zeolite acid sites in stabilizing molecularly dispersed $\mathrm{PdO}\left(\right.$ or $^{\mathrm{Pd}^{2+}}$ ) species is well known, and they can be the active center for the reaction. However, the structures of $\mathrm{Pd}$ active species during the reaction and the interactions of Pd species with molecules present in the reaction media still remain ambiguous [7].

In a previous study with $\mathrm{Pd} /$ zeolite catalysts, the NO decomposition reaction using mordenite prepared in two different forms was evaluated and compared with a catalyst supported on commercial mordenite [8]. Although the samples exhibited similar levels of activity the selectivity was different. The samples prepared with mordenite synthesized from clay led to lower $\mathrm{N}_{2} \mathrm{O}$ formation than mordenite synthesized from standard reagents. The selectivity to $\mathrm{N}_{2} \mathrm{O}$ was lower when the commercial support was used. Therefore, the present study was aimed to characterize the Pd species present in these catalysts that are 
responsible for the observed activity and selectivity. Different techniques, such as hydrogen chemisorption, temperature-programmed reduction, infrared spectroscopy of $\mathrm{CO}$ and NO molecules adsorbed onto the catalysts, diffused reflectance spectroscopy in the UV-Vis region and temperature-programmed desorption of $\mathrm{NO}$ were used.

\section{Experimental}

\subsection{Catalyst Preparation}

The mordenite zeolite support used in this study was synthesized by the Environmental Chemistry Laboratory (LAQAM) of URI-Campus de Erechim, along with a commercial mordenite (CBV 10A) provided by ITQValence-Spain, MOR-COM. The synthesized mordenite was prepared by standard IZA methods [9] using two distinct procedures: (a) using sodium aluminate as the source of aluminum and Aerosil silica (Degussa) as the source of silicon (MOR-IZA) and (b) using a natural clay (MINA) as an alternative $\mathrm{Al}$ and $\mathrm{Si}$ source [8] (MOR-ARG).

The supports were pretreated at $673 \mathrm{~K}$ for $5 \mathrm{~h}$ with a heating rate of $5 \mathrm{~K} \mathrm{~min}^{-1}$. Intermediate $1 \mathrm{~h}$ steps at 423 and $573 \mathrm{~K}$ were used before the final desired temperature was reached. Palladium was incorporated into the supports through ionic exchange with a $0.8 \mathrm{mmol} \mathrm{L}^{-1}$ solution of $\mathrm{Pd}\left(\mathrm{NO}_{3}\right)_{2}$ with a solid/solution concentration of $30 \mathrm{~g} \mathrm{~L}^{-1}$ at $323 \mathrm{~K}$ for $36 \mathrm{~h}$. The material was filtered, washed with deionized water, dried at $373 \mathrm{~K}$ for $24 \mathrm{~h}$ and calcinated at $673 \mathrm{~K}$ under a synthetic air flow for $5 \mathrm{~h}$. This method was adapted from Aylor et al. [10].

\subsection{Catalysts Characterization}

The chemical composition of the solids was determined by optical emission spectrometry with an inductively coupled plasma (ICP-OES) source. The equipment was manufactured by Perkin-Elmer (model Optima 2000 DV) and used for the analysis of $\mathrm{Na}, \mathrm{Pd}$ and $\mathrm{Al}$. The samples were dissolved in a solution of $\mathrm{HCl}: \mathrm{HNO}_{3}(6: 2)$ at $383 \mathrm{~K}$. Experiments involving the temperature-programmed desorption of NO (TPD) were performed in a quadrupolar mass spectrometer (Balzers-Prisma) coupled with an analytical Quadstar system. The samples were pretreated at $573 \mathrm{~K}$ for $3 \mathrm{~h}$ with hydrogen, purged with helium for $30 \mathrm{~min}$ and cooled to room temperature. The adsorption was carried out with a flow rate of $50 \mathrm{~mL} \mathrm{m^{-1 }}$ with $500 \mathrm{ppm}$ of NO in helium until the signal on the detector stabilized. After stabilization, the catalyst sample was heated at $20 \mathrm{~K} \mathrm{~min}^{-1}$ to $773 \mathrm{~K}$ in helium flow $\left(50 \mathrm{~mL} \mathrm{~min}{ }^{-1}\right)$, holding the final temperature for $1 \mathrm{~h}$.
For FTIR characterization, catalyst samples of approximately $40 \mathrm{mg}$ were pressed to form transparent disks $13 \mathrm{~mm}$ in diameter that were mounted in the beam path of an IR cell sealed with $\mathrm{CaF}_{2}$ windows. The samples were calcinated calcined in air at $573 \mathrm{~K}$ and then reduced with hydrogen at the same temperature. Subsequently, the samples were cooled to room temperature under vacuum and dosed with 5 Torr of either CO or NO. After a few minutes, the IR spectra were obtained. The cell was evacuated and a new spectrum was obtained to observe the stability of the bands. After the adsorption of $\mathrm{CO}$, the oxidation and reduction treatments were repeated prior to the adsorption of NO. An FTIR spectrum taken under vacuum conditions was used as the background. Infrared spectra were recorded using a NICOLET 20 DXB instrument with a $4 \mathrm{~cm}^{-1}$ resolution.

The fraction of exposed palladium atoms $(\mathrm{H} / \mathrm{Pd})$ was obtained from $\mathrm{H}_{2}$ chemisorption measurements. The experiments were performed in a volumetric apparatus in the 10-100 torr pressure range. Samples of $250 \mathrm{mg}$ were previously reduced at $573 \mathrm{~K}$ in flowing $\mathrm{H}_{2}$ and evacuated overnight at the same temperature. The double isotherm method was used to determine the amount of irreversibly chemisorbed hydrogen, $(\mathrm{H} / \mathrm{Pd})_{\text {irr }}$, at room temperature. The first isotherm measured the amount of absorbed and chemisorbed hydrogen. Subsequently the amount of absorbed hydrogen and that weakly chemisorbed was measured after evacuation at room temperature for $30 \mathrm{~min}$. The amount of irreversible chemisorbed hydrogen was determined by subtracting the second isotherm from the first.

Diffuse Reflectance Spectroscopy analysis in the UVvis region (DRS UV-vis) was carried out with a Cary 500 Spectrophotometer using $\mathrm{BaSO}_{4}$ as a reference. The references for these experiments were the catalyst supports. The samples were previously calcined in air at $673 \mathrm{~K}$.

Temperature programmed reduction measurements were performed in a conventional equipment using a $\mathrm{H}_{2}(5 \%) / \mathrm{Ar}$ mixture with a flow rate of $30 \mathrm{~mL} / \mathrm{min}^{-1}$ up to $773 \mathrm{~K}$. Samples were previously treated at 573 or $673 \mathrm{~K}$ in air, purged in Ar and cooled to $243 \mathrm{~K}$.

\section{Results and Discussion}

The results obtained for the chemical compositions of the samples are summarized in Table 1 . The different zeolites have a BET area in the range $315-360 \mathrm{~m}^{2} / \mathrm{g}$, a similar $\mathrm{Na}$ content but different $\mathrm{SiO}_{2} / \mathrm{Al}_{2} \mathrm{O}_{3}$ ratios. The PdMOR-COM and PdMOR-IZA catalysts showed metal contents of approximately $0.7-0.8 \%$ by weight. The metal loading on PdMOR-ARG was lower. 
Table 1 Main catalysts properties

* $(\mathrm{H} / \mathrm{Pd})_{\mathrm{abs}}$ values in parenthesis

\begin{tabular}{llllllr}
\hline Sample & $\mathrm{Pd}(\mathrm{wt} \%)$ & $\mathrm{Al}(\mathrm{wt} \%)$ & $\mathrm{Pd} / \mathrm{Al}$ & $\mathrm{SiO}_{2} / \mathrm{Al}_{2} \mathrm{O}_{3}$ & $\mathrm{Na}(\mathrm{wt} \%)$ & $(\mathrm{H} / \mathrm{Pd})_{\mathrm{irr}}{ }^{*}(\%)$ \\
\hline PdMOR-COM & 0.77 & 4.14 & 0.05 & 12 & 2.85 & $15.0(0.47)$ \\
PdMOR-IZA & 0.72 & 2.70 & 0.07 & 18 & 3.31 & $9.5(0.55)$ \\
PdMOR-ARG & 0.42 & 2.44 & 0.04 & 20 & 3.29 & $6(0.44)$ \\
\hline
\end{tabular}

As described above the catalysts samples used in the present study were calcined in air at $673 \mathrm{~K}$ after the addition of $\mathrm{Pd}$. For the hydrogen chemisorption measurements they were reduced in flowing $\mathrm{H}_{2}$ at $573 \mathrm{~K}$. The results presented in Table 1 indicate a low uptake of $\mathrm{H}_{2}$ for all samples, which suggests the presence of large $\mathrm{Pd}$ particles.

The sample with the higher metal dispersion after reduction at $573 \mathrm{~K}$ was PdMOR-COM. The H/Pd ratio of 0.15 corresponds to a particle size of $7.5 \mathrm{~nm}$ $(\mathrm{d}(\mathrm{nm})=1.12 /(\mathrm{H} / \mathrm{Pd}))$. In this case the average Pd particle size was also checked by TEM and was found to be $5 \mathrm{~nm}$ in close agreement with the chemisorption measurement. The behavior of the PdMOR-IZA sample was similar but the metal dispersion was lower; 9.5\%. For the PdMORARG sample the low $\mathrm{H} / \mathrm{Pd}$ ratio, $6 \%$, was surprising taking into account the lower metal loading.

Suspecting an effect of the pretreatment conditions on the $\mathrm{Pd}$ dispersion the chemisorption measurement for the PdMOR-ARG sample was repeated after calcination in air at 523 and $673 \mathrm{~K}$ followed by reduction at 573 and $673 \mathrm{~K}$. No change in dispersion was observed.

Using the back-sorption isotherms and taking into account the $(\mathrm{H} / \mathrm{Pd})_{\text {irr }}$ values the amount of absorbed $\mathrm{H}_{2}$ forming the $\beta$-hydride was estimated. As observed in Table 1 the $(\mathrm{H} / \mathrm{Pd})_{\mathrm{abs}}$ values at 40 Torr and $297-298 \mathrm{~K}$ were in the $0.44-0.55$ range which are close to that reported for bulk $\mathrm{Pd}$ (0.65) [11]. Consequently Pd particles are formed on all samples after $\mathrm{H}_{2}$ reduction at $573 \mathrm{~K}$.

In order to obtain information on the oxidation-reduction behavior of the catalysts samples comparative TPR experiments were carried out. Before the experimental results emerging from the TPR study are presented it is important to recall that the chemical state and the particle size of the $\mathrm{Pd}$ phase on $\mathrm{Pd} /$ zeolite catalysts depends strongly on the pretreatment conditions; the atmosphere and the temperature. It has been shown by Homeyer and Sachtler [12] that oxidation of $\mathrm{Pd} / \mathrm{NaY}$ catalysts above $573 \mathrm{~K}$ lead to the formation of $\mathrm{PdO}$ that reacts with surface protons leading to well dispersed $\mathrm{Pd}^{2+}$ species. The reduction of these species was characterized by a TPR profile where the $\mathrm{H}_{2}$ consumption peak appeared at $450 \mathrm{~K}$.

On the other hand they found that an oxidizing pretreatment below $573 \mathrm{~K}$ leads to the formation of PdO. In this case the reduction process takes place at lower temperature forming Pd metal particles.
The reduction profiles for the PdMOR-COM and PdMOR-ARG samples oxidized at $673 \mathrm{~K}$ are presented in Fig. 1a-b. The broad peak at low temperature $(\cong 250-$ $260 \mathrm{~K})$ is due to Ar desorption from the zeolite support. The reduction of $\mathrm{Pd}$ took place at $\cong 304 \mathrm{~K}$, and the presence of a hydride decomposition negative peak was clearly observed at $347 \mathrm{~K}$. Both the $\mathrm{H}_{2}$ consumption and the hydride decomposition peaks were larger on PdMORCOM in view of the higher Pd loading. The amount of $\mathrm{H}_{2}$
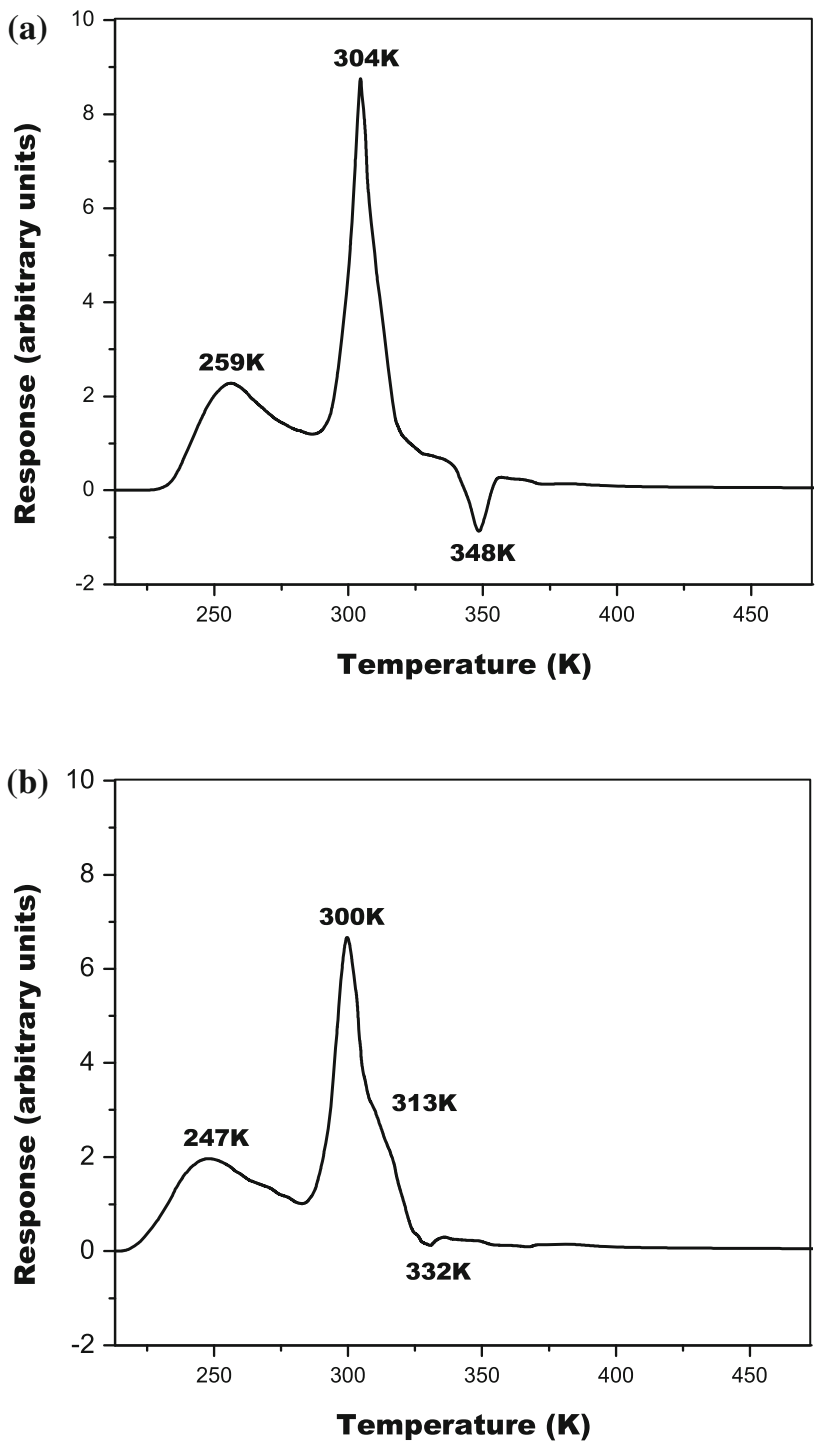

Fig. 1 TPR of PdMOR-COM (a) and PdMOR-ARG (b) catalysts after calcination at $823 \mathrm{~K}$ 
consumed during the reduction process on PdMOR-COM and PdMOR-ARG corresponds to the reduction of $90-95 \%$ of the Pd present.

When the oxidation pretreatment was performed at $573 \mathrm{~K}$ the reduction occurred at $\cong 273 \mathrm{~K}$ and the hydrogen consumption peak overlapped with that of Ar desorption. In this case the amount of $\mathrm{H}_{2}$ consumed was equivalent to reduction of $\cong 80 \%$ of the metal. This result indicates that the formation of $\mathrm{PdO}$ or $\mathrm{Pd}^{2+}$ is not complete at $573 \mathrm{~K}$.

The effect of the oxidation temperature on the subsequent reduction process is similar to that observed by Homeyer and Sachtler [12] mentioned above. Oxidation at $>573 \mathrm{~K}$ generates mainly $\mathrm{Pd}^{2+}$ species that are reduced at $304 \mathrm{~K}$. On the other hand when the oxidation pretreatment is carried out at $\leq 573 \mathrm{~K} \mathrm{PdO}$ particles are formed and the reduction temperature is shifted to a lower temperature.

Figure 2 presents the $\mathrm{CO}$ adsorption spectra of the reduced PdMOR catalysts. The spectra showed that bands corresponding to $\mathrm{CO}$ adsorbed on the metallic palladium in the linear (at approximately $2100 \mathrm{~cm}^{-1}$ ) and bridge forms (below $2000 \mathrm{~cm}^{-1}$ ) are well defined in the PdMOR-COM and PdMOR-IZA catalysts. These results confirm that Pd could be obtained in a reduced form after the hydrogen treatment at $573 \mathrm{~K}$. In the PdMOR-COM catalyst, the band corresponding to the bridge form of adsorbed $\mathrm{CO}$ is asymmetric and appears at a lower frequency, thereby indicating a stronger adsorption in several crystal planes [13]. According to the IR spectrum in Fig. 2c, the intensity of the band due to linear $\mathrm{CO}$ is lower than that due to multiple coordinated species which is in accordance with the small metal dispersion of PdMOR-IZA as compared to PdMOR-COM.

The spectrum of the PdMOR-ARG catalyst is quite distinct. In Fig. $2 b$ the noise level is high due to the relatively low transmittance of this sample (observed in the background spectrum) and the low Pd content. The bands due to adsorbed $\mathrm{CO}$ are weak and wide, and those corresponding to $\mathrm{CO}$ adsorbed in the linear form appear in a broad frequency range suggesting the simultaneous presence of $\mathrm{Pd}^{\mathrm{o}}, \mathrm{Pd}^{+}$or $\mathrm{Pd}^{2+}$ species after reduction. Due to the quality of the spectrum specific band assignments cannot be given. The linear bands disappear completely under vacuum, which suggests a weak interaction.

The spectrum of $\mathrm{CO}$ adsorption at room temperature on PdMOR-COM was also obtained after oxidation at $673 \mathrm{~K}$. In this case a sharp an intense band was observed at $2147 \mathrm{~cm}^{-1}$ which is assigned to $\mathrm{CO}$ located on $\mathrm{Pd}^{2+}$. A similar band was detected when $\mathrm{CO}$ adsorption at room temperature was performed on a sample used for $\mathrm{NO}$ decomposition at $673 \mathrm{~K}$, indicating the redispersion of $\mathrm{Pd}$ into $\mathrm{Pd}^{2+}$ ions. .

The results of the FTIR study of NO adsorption are shown in Fig. 3. The PdMOR-COM and PdMOR-IZA
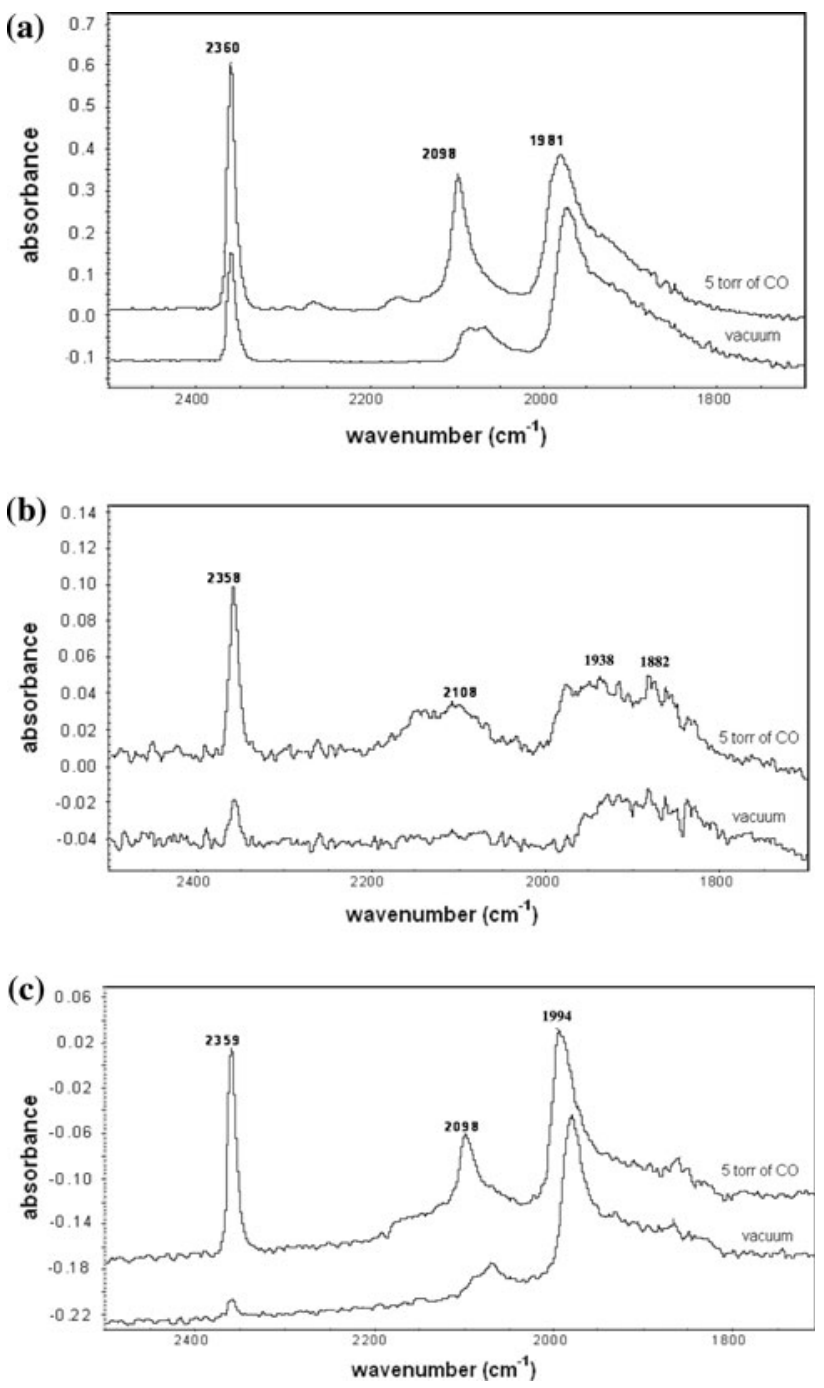

Fig. 2 Infrared Spectra of Adsorbed $\mathrm{CO}$ after reduction at $573 \mathrm{~K}$. a PdMOR-COM, (b) PdMOR-ARG and (c) PdMOR-IZA catalysts

catalysts reveal a band at $1744 \mathrm{~cm}^{-1}$ corresponding to linear $\mathrm{NO}$ adsorbed onto $\mathrm{Pd}^{\mathrm{o}}$. The intensity of this band is greater for the catalyst prepared with the commercial mordenite (MOR-COM) followed by MOR-IZA. This is in accordance with the $\mathrm{CO}$ adsorption and hydrogen chemisorption measurements that demonstrated the higher metal dispersion of PdMOR-COM. All samples showed a band at $1876 \mathrm{~cm}^{-1}$ that has been previously observed on $\mathrm{Pd} / \mathrm{H}$ MOR and Pd/H-ZSM5 catalysts calcined in oxygen [14, 15] that is assigned to NO molecules adsorbed onto oxidized $\mathrm{Pd}\left(\mathrm{Pd}^{2+}\right)$. Consequently in our samples a fraction of $\mathrm{Pd}$ remains in an oxidized form after the hydrogen treatment.

On the PdMOR-ARG sample (Fig. 3b) the bands are weak and the spectrum is more complex. The NO- $\mathrm{Pd}^{\circ}$ band appears at a slightly higher frequency, $1754 \mathrm{~cm}^{-1}$ and it has an intensity comparable to that of $\mathrm{Pd}^{2+} \mathrm{NO}$ located at 

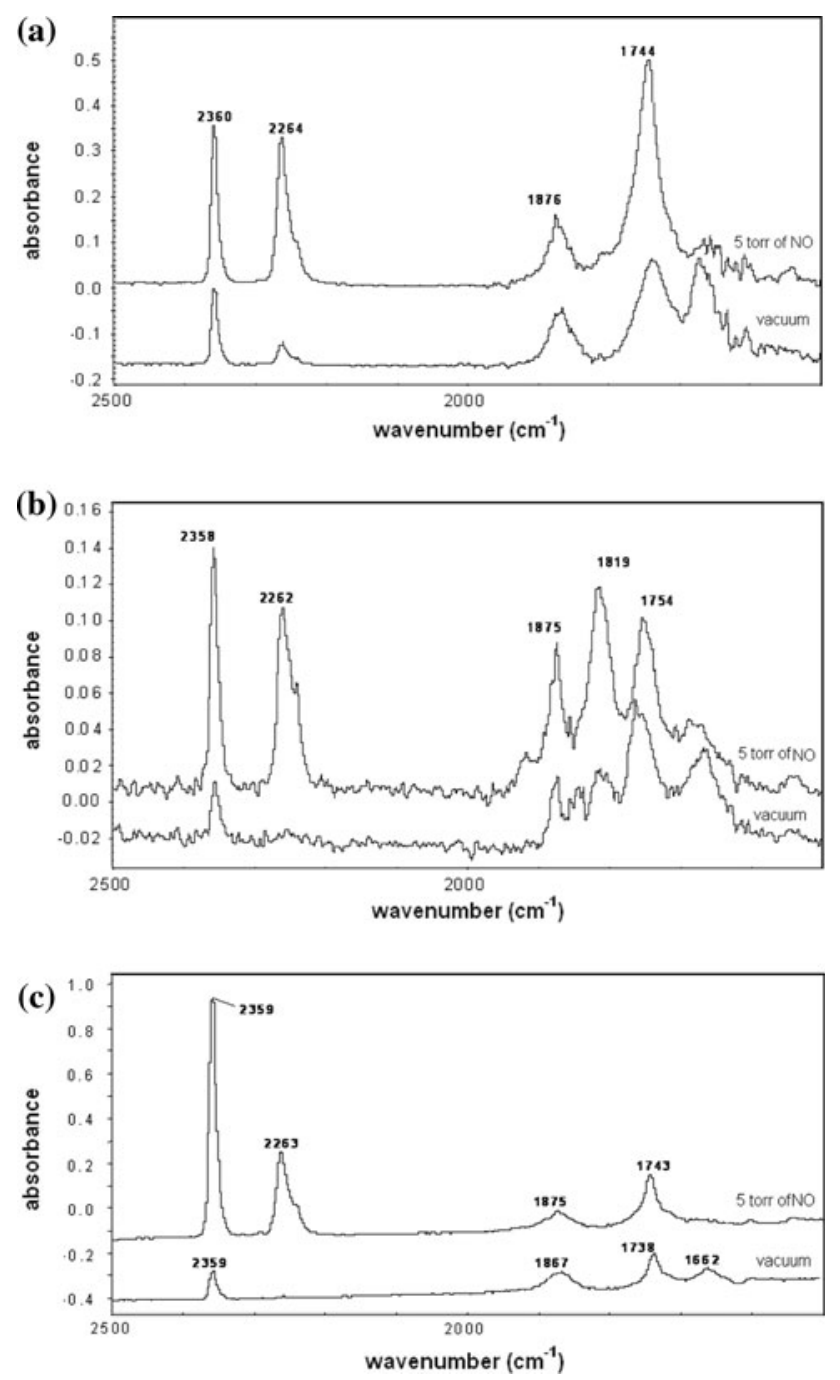

Fig. 3 Infrared Spectra of Adsorbed NO after reduction at $573 \mathrm{~K}$. a PdMOR-COM, (b) PdMOR-ARG catalyst and (c) PdMOR-IZA catalysts

$1875 \mathrm{~cm}^{-1}$. Consequently the fraction of oxidized $\mathrm{Pd}$ is higher on PdMOR-ARG as compared to PdMOR-COM or PdMOR-IZA. In addition a strong band appears at $1819 \mathrm{~cm}^{-1}$ that is absent in the other samples. This band can be attributed to $\mathrm{Pd}^{+}$species, thereby reinforcing the premise that this catalyst in the reduced state contains $\mathrm{Pd}$ in oxidizing form. Studies conducted by Aylor et al. [10] on PdZSM-5 attributed the appearance of a band at $1815 \mathrm{~cm}^{-1}$ to cationic Pd species.

The spectra in Fig. 3 shows that adsorption of $\mathrm{NO}$ on the reduced samples forms a band at $2260 \mathrm{~cm}^{-1}$ that diminishes and almost completely disappears when exposed to vacuum. A band at $\cong 2230 \mathrm{~cm}^{-1}$ has been observed on previous studies carried out on H-MOR and PdH-MOR after an oxidizing pretreatments [14] and it has been tentatively assigned to $\mathrm{NO}_{2}$ adsorption on the zeolite.
The spectra of Figs. 2 and 3 also show a very intense band between 2358 and $2360 \mathrm{~cm}^{-1}$ after exposure to 5 Torr of $\mathrm{CO}$ or NO. The frequency is very similar to that of $\mathrm{CO}_{2}$ gas, although it belongs to an adsorbed molecule. A similar band was obtained upon exposing a reduced sample to $\mathrm{CO}_{2}$. It is observed that the intensity of the band was higher than that of $\mathrm{CO}$ and $\mathrm{NO}$ indicating that corresponds to a molecule located on the support surface. In all of the studied catalysts, the band was slowly eliminated under vacuum. The formation of $\mathrm{CO}_{2}$ during $\mathrm{CO}$ adsorption may arise from the reaction of $\mathrm{CO}$ with oxidized $\mathrm{Pd}$ species. $\mathrm{CO}$ disproportionation is unlikely to occur at room temperature. More intriguing is the appearing of $\mathrm{CO}_{2}$ upon $\mathrm{NO}$ adsorption. One possibility is the formation of $\mathrm{CO}_{2}$ by reaction of surface carbonates with $\mathrm{NO}$ or $\mathrm{NO}_{2}$. Supporting this explanation we found that calcinations of the samples in air at $673 \mathrm{~K}$ prior to reduction practically eliminates the $\mathrm{CO}_{2}$ band at $2360 \mathrm{~cm}^{-1}$.

The DRS UV-vis spectra of the mordenite-supported Pd catalysts are shown in Fig. 4. Characterization of the samples by DRS UV-vis after calcination in air provides information on a surface condition that resemble the state of the catalysts after the NO decomposition reaction at $673 \mathrm{~K}$. A previous UV-Vis study of PdMOR catalysts was performed by Shimizu et al. [7] on samples calcined at $823 \mathrm{~K}$. Based on this work the band around $200 \mathrm{~nm}$, observed in all three catalysts, has been assigned to charge transfer between oxygen of the support and $\mathrm{Pd}^{+2}$ (LMCT). The bands extending from around $300 \mathrm{~nm}$ to $450 \mathrm{~nm}$, are due to $\mathrm{d}-\mathrm{d}$ transitions of $\mathrm{Pd}^{2+}$ ions affected by different oxygen environments and/or the presence of water $(\mathrm{PdO}$; $\left.\mathrm{Pd}\left(\mathrm{H}_{2} \mathrm{O}\right)_{4}^{2+} ; \mathrm{Pd}\left(\mathrm{O}_{\mathrm{z}}\right)_{n}^{2+}\right)$. On samples calcined at high temperature (well dehydrated) the d-d band has been observed at $460-480 \mathrm{~nm}$ [7]. In our case the lower calcination

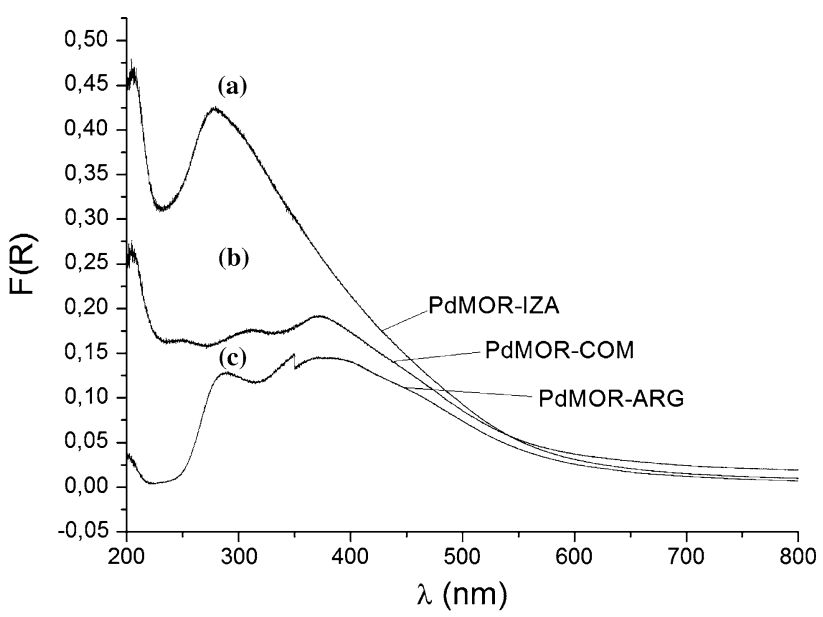

Fig. 4 Diffuse Reflectance Spectra in the visible region of PdMORIZA (a), PdMOR-COM (b) and PdMOR-ARG (c) catalysts after calcinations in air at $673 \mathrm{~K}$ 
Table 2 TPD of NO and catalytic results

* $\mathrm{N}_{2} \mathrm{O}$ formed after $200 \mathrm{~min}$ of reaction at low conversion (below 20\%). $T=673 \mathrm{~K}$

\begin{tabular}{llllc}
\hline Catalysts & $\mathrm{NO}\left(\mu \mathrm{mol} \mathrm{g}{ }^{-1}\right.$ cat $)$ & $\mathrm{N}_{2}\left(\mu \mathrm{mol} \mathrm{g}{ }^{-1}\right.$ cat $)$ & $\mathrm{N}_{2} \mathrm{O}\left(\mu \mathrm{mol} \mathrm{g}^{-1}\right.$ cat $)$ & $\mathrm{N}_{2} \mathrm{O}^{*}(\mathrm{ppm})[8]$ \\
\hline PdMOR-COM & 6.74 & 9.02 & 57.2 & 4 \\
PdMOR-IZA & 5.02 & 3.95 & 37.15 & 18 \\
PdMOR-ARG & 2.42 & 3.85 & 29.66 & 8 \\
\hline
\end{tabular}

temperature $(673 \mathrm{~K})$ and the exposure of the samples to room air lead to a UV-vis spectrum showing that different oxidized forms of $\mathrm{Pd}$ are present in the PdMOR catalysts. For example a band at $300 \mathrm{~nm}$ is well defined on PdMORIZA, also present but less intense on PdMOR-ARG and nearly absent on PdMOR-COM.

Analyses of TPD of NO (Table 2) showed that there is a concomitant reaction during the thermal desorption that, with heating, produces $\mathrm{N}_{2}$ and $\mathrm{N}_{2} \mathrm{O}$. A nitrogen mass balance shows that the amount of nitrogen containing products desorbing is higher for PdMOR-COM followed by PdMOR-IZA. Taking into account that these catalysts have almost the same metallic content, the behavior is attributed to the difference in metal dispersion. On the other hand the lower amount of $\mathrm{NO}, \mathrm{N}_{2}$ and $\mathrm{N}_{2} \mathrm{O}$ desorbing from PdMORARG mainly reflects the effect of the low metal loading. The selectivity to $\mathrm{N}_{2} \mathrm{O}\left(\mathrm{N}_{2} \mathrm{O} /\left(\mathrm{N}_{2} \mathrm{O}+\mathrm{N}_{2}\right)\right)$ follows the order PdMOR-IZA (0.90) $>$ PdMOR-ARG (0.88) $>$ PdMORCOM (0.86) in accordance with the results of the NO decomposition reaction [see Table 2]. It has been demonstrated by $\mathrm{Xu}$ and Goodman [16] that the formation of $\mathrm{N}_{2} \mathrm{O}$ depends strongly on the $\mathrm{Pd}$ particle size; large particles favor the production of $\mathrm{N}_{2} \mathrm{O}$. Based on the chemisorption and FTIR results Pd particles are present on PdMOR-COM and PdMOR-IZA after reduction at $673 \mathrm{~K}$ and they are responsible for the high initial catalytic activity for $\mathrm{NO}$ decomposition [8]. The only observable difference between these samples is the metal dispersion. NO dissociation produces nitrogen and oxygen atoms. Oxygen, that remains on the metal surface, inhibits the adsorption of NO and lead to oxidation of the metal $(\mathrm{PdO})$, causing deactivation and $\mathrm{N}_{2} \mathrm{O}$ formation. This behavior is similar to that found on $\mathrm{Al}_{2} \mathrm{O}_{3}$ supported $\mathrm{Pd}$ [17]. On $\mathrm{Pd} /$ zeolites if the reaction is carried out at $>573 \mathrm{~K}$ the acidic support allows the redispersion of $\mathrm{PdO}$ leading to $\mathrm{Pd}^{2+}$ formation. The amounts of $\mathrm{PdO}$ and $\mathrm{Pd}^{2+}$ produced will depend on the reaction temperature and the metal loading. The support material may also play a role. On PdMOR-IZA the low metal dispersion relative to that of PdMOR-COM and the formation of different oxidized species in the presence of oxygen as reveled by the DRS UV-vis study may lead to a larger fraction of $\mathrm{PdO}$ particles where the formation of $\mathrm{N}_{2} \mathrm{O}$ is favored. Again this interpretation one may argue that the production of $\mathrm{N}_{2} \mathrm{O}$ on PdMOR-ARG is lower with a metal dispersion of $6 \%$. However the FTIR spectra of adsorbed NO has demonstrated that a large fraction of $\mathrm{Pd}$ remains in an oxidized form after the hydrogen treatment at $573 \mathrm{~K}$. If this fraction is unable to chemisorb hydrogen. The actual $\mathrm{Pd}$ dispersion is higher than $6 \%$.

Despite the mentioned differences in selectivity, the three PdMOR catalysts exhibit a comparable activity for NO decomposition [8]. They showed a conversion of $100 \%$ for a running time of about 100 min followed by a steady deactivation. In view of the similar metal loading this behavior is understandable for the PdMOR-COM and PdMOR-IZA samples. On the other hand the high catalytic activity of PdMOR-ARG with a much lower loading is surprising. The FTIR results indicate that $\mathrm{Pd}^{2+}$ ions are still present in this sample after reduction at $573 \mathrm{~K}$. Moreover under reaction conditions the low metal loading $(0.42 \%)$ facilitates the process of oxidative redispersion increasing the concentration of $\mathrm{Pd}^{2+}$ sites that became active for $\mathrm{NO}$ adsorption under reaction conditions [7]. We suspect that these $\mathrm{Pd}^{2+}-\mathrm{NO}$ entities enhance the dissociation of NO. However the extent of oxidative redispersion under reaction conditions will be limited by the availability of surface protons created during the hydrogen treatment. Consequently the formation of stable $\mathrm{PdO}$ particles eventually leads to catalyst deactivation.

\section{Conclusion}

The characterization of PdMOR catalysts under reducing and oxidizing conditions has been performed in order to explain the activity and selectivity for the NO decomposition reaction. A sample prepared with commercial mordenite (PdMOR-COM) and two preparations (PdMORIZA; PdMOR-ARG) obtained by a standard IZA method using different sources of $\mathrm{Si}$ and $\mathrm{Al}$ were compared. After reduction at $573 \mathrm{~K} \mathrm{Pd}^{\mathrm{o}}$ particles are formed on PdMORCOM and PdMOR-IZA the metal dispersion being higher for the former sample. The FTIR results demonstrate that a fraction of $\mathrm{Pd}$ in an oxidized form $\left(\mathrm{Pd}^{2+} ; \mathrm{Pd}^{+}\right)$remains in all samples after reduction and this situation predominate on PdMOR-ARG mainly due to the lower Pd content. These $\mathrm{Pd}$ species are formed by oxidative redispersion during air calcination at $>573 \mathrm{~K}$. The TPR results demonstrate that the reduction of ionic Pd is more difficult than that of PdO. The TPD of adsorbed NO have shown that the amount of desorbing products depends mainly on the fraction of exposed $\mathrm{Pd}$ atoms and the selectivity to $\mathrm{N}_{2} \mathrm{O}$ is 
in reasonable agreement with the results obtained for the NO decomposition reaction at $673 \mathrm{~K}$. The lower metal dispersion of the reduced PdMOR-IZA sample and the distinct oxygen environment of the zeolite support reveled by the DRS UV-vis study may favor the formation of PdO and the production of $\mathrm{N}_{2} \mathrm{O}$. The lower metal loading of PdMOR-ARG and the higher concentration of oxidized species lead to a catalyst with an activity and selectivity comparable to that of PdMOR-COM.

Acknowledgements The Brazilian agencies CNPq, FAPERGS, COPESUL and CONICET (Argentine) are acknowledged for their financial support.

\section{References}

1. Mosqueda-Jiménez BI, Jentys A, Seshan K, Lercher JA (2003) Appl Catal B 43:105

2. Cordatos H, Gorte RJ (1996) J Catal 159:112
3. Ramachandran B, Herman RG, Choi S, Stenger HG, Lyman CE, Sayle JS (2000) Catal Today 55:281

4. Pieterse JAZ, Booneveld S (2007) Appl Catal B 73:327

5. Iwamoto M, Yahiro H, Mine Y, Kagawa S (1989) Chem Lett $18: 213$

6. Chen H-Y, Wang X, Sachtler WHM (2000) Appl Catal A 194195:159

7. Shimizu K-C, Okada F, Nakamura Y, Satsuma A, Hattori T (2000) J Catal 195:151

8. de Oliveira AM, Baibich IM, Machado NRCF, Mignoni ML, Pergher SBC (2008) Catal Today 133-135:560

9. International Zeolite Association. http://www.iza-online.org

10. Aylor AW, Lobree LJ, Reimer JA, Bell AT (1997) J Catal 172:453

11. Frazier GA, Glosser R (1980) J Less Common Met 74:89

12. Homeyer T, Sachtler WMH (1989) Appl Catal 54:189

13. Bradshawe AW, Hoffmann FM (1978) Surf Sci 72:513

14. Descorme C, Gélin P, Lécuyer C, Primet M (1998) J Catal 177:352

15. Pommier B, Gélin P (2001) Phys Chem Chem Phys 3:1138

16. Xu X, Goodman DW (1994) Catal Lett $24: 33$

17. Pisanu AM, Gigola CE (1999) Appl Catal B 20:179 